\title{
Current status and perspectives for education in Latin America
}

\author{
Ana Luiza Machado \\ Director, UNESCO Regional Office - Santiago \\ Enrique Delpiano 29 \\ Santiago, Chile Codigo Postal 6651692
}

\begin{abstract}
Education in Latin America is an important part of social policy. Although huge strides were made in the last decade, a region of disparity between the rich and poor needs to focus on the reduction of inequality of access and provision if it is to hope for qualitative change. Detailed achievements and challenges are presented, with an emphasis on improving school enrolment and a change to curriculum relevant for the future and local community and business involvement. Change will be achieved by a combination of new teachers, new management and leadership, and the involvement of all society.
\end{abstract}

Keywords: Latin America, change, literacies, inequities, society

\section{INTRODUCTION}

Education has become increasingly important within governmental policy, and particularly social policy, in Latin America. As a sector, it receives a large proportion of public resources. A review of declarations from meetings of the region's Presidents and Education Ministers during the last decade reveals the high expectations that policy makers and society have for education. The causal links between education and individual and social development, education and overcoming poverty, education and living together in peace, are recurrent themes in the political discourse.

In view of these high political and social expectations of education, it is important to start with the context of our region, and consider some factors

The original version of this chapter was revised: The copyright line was incorrect. This has been corrected. The Erratum to this chapter is available at DOI: 10.1007/978-0-387-35403-3_29 
regarding the status of education during the last decade. Then, we can look ahead to the future social and economic contexts and the challenges that the education sector faces.

In the last 10 years, the population of Latin America grew by $18 \%$, from 430 to 508 million inhabitants. Of this increase of 78 million, almost all - 76 million - were born in urban areas. Less than $2 \%$ of the increase - 1.5 million - were born in rural areas. This increase was accompanied by moderate economic growth - averaging 3.6\% annually. Latin America has the most unequal income distribution in the world. $40 \%$ of the poorest homes earn between 10 and $17 \%$ of national income, while the $10 \%$ of the wealthiest homes account for between 30 and $40 \%$ of total income. Poverty remains at high levels; by the end of the nineties, $36 \%$ of households were below the poverty line. Economic progress during the decade merely permitted the continent to return to 1980 levels.

Politically, the nineties were marked by the attainment of peace within the Central America subregion and by the recovery and consolidation of democracies throughout the continent. Nevertheless, the region continues to suffer from high rates of violence rooted in exclusion and poverty. From the cultural perspective, and seen from outside, our continent appears to be one of the most homogeneous groups of nations in the world. But viewed from inside, the region is a polychromatic mosaic of cultures with hundreds of dialects, dozens of languages, and countless ethnic groups, customs, and beliefs.

\section{STATUS REPORT OF EDUCATION IN LATIN AMERICA}

The following status report is largely the result of the Assessment of Commitments to Education For All in the Year 2000. The commitments of this programme were:

- Expansion of early childhood care and development activities;

- Universal access to basic education and the satisfaction of basic learning needs of the entire population;

- Reduction of the illiteracy rate by one-half by the year 2000 , and increase of basic education and training services for young people and adults;

- Increasing availability of basic skills education and training for young people and adults;

Providing, through education, knowledge and skills to help people maximise their potential and improve the quality of their lives. 
A general assessment of the development of education over the past decade reveals that although there has been real progress in the region, the goals proposed at Jomtien in 1990 have not all been achieved. There is much to be done in order to turn 'education for all, education from birth, education as a lifelong process, inclusive education' into a reality. But the decade witnessed the construction of the political and technical foundations necessary to make the achievement of these goals possible. So there is now an awareness, a national consensus, some clear diagnoses (including about what we do not know), and some examples of successful policies for further development. Some significant points of recent years for each level of education can be reported.

\subsection{Early childhood care and education}

Coverage of early childhood care and education programmes increased for the ages closest to primary school entry level, principally in urban areas, producing a substantial increase in the numbers of boys and girls who now enter primary school with some formal early education experience. But programmes for younger children - from birth to 3 years - are still limited.

This phase has benefited from a growing participation of parents and the community in these programmes, particularly for the age groups and social classes that receive less State attention. It should be noted that the countries that have the greatest coverage at this level are those in which the State participates widely in the provision of such services under various guises both formal and non-formal, conventional and non-conventional.

\subsection{Primary education and learning results}

Formally organised primary education was the principal vehicle used by governments to deliver education services to the majority of the population. The last decade witnessed the achievement of universal access to primary education, except for some population groups in rural areas. Still, a serious and persistent problem is the high numbers (between 30 and $40 \%$ ) of children who do not stay in school until the fifth grade (see Figure 1). 


\section{Survival rate to grade 5 \\ of primary education: \\ Ranges for Latin America}

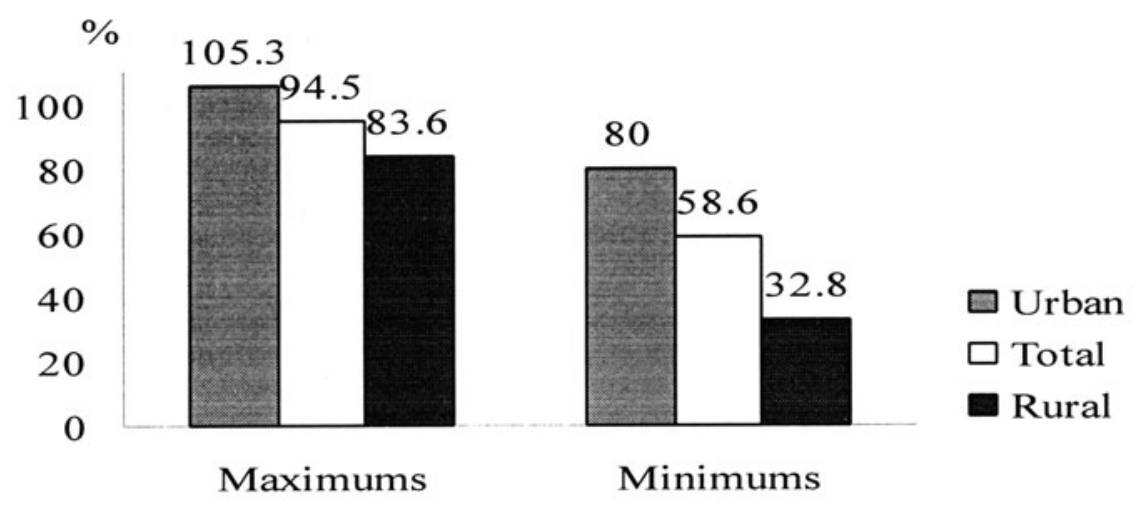

End of the Period

Figure 1. Attendance rate to grade 5 of primary education: Ranges in Latin America

Among major strategies used to improve quality and promote equality were:

- Strategies aimed at general improvement in:

1. Curricular reform

2. School autonomy

3. Provision of teaching resources

4. Initial and in service teacher training

5. Increasing the time dedicated to learning;

- Focused strategies aimed at improving quality with equity by applying 'affirmative action' criteria;

- Programs for accessing and measuring the quality of education.

Although there is no consensus on the meaning of 'educational quality', there is agreement regarding the importance of measuring learning results, in order to estimate the levels of knowledge, skills, and abilities that students acquire. For an over-all view of learning results, we have used information from the Latin American Laboratory for the Assessment of Educational Quality, which published comparable data for 13 countries within the region. The principal findings of the study show the following. 
1. A high percentage of student achievement scores are best explained by factors outside of the school itself. Among those that best correlate to student test scores are social and family context variables.

2. But an important percentage of the variance in student achievement is explained by factors linked to the school. This is encouraging because it means that significant opportunities exist to develop policies aimed at changing the current situation and at considerably improving student achievement.

3. Girls perform better than boys in language, while boys have better scores in mathematics.

4. With the exception of one country, urban schools showed better student results than rural schools.

5. The level of language achievement is low when pedagogical objectives are not met. Children are learning to read, but not to understand or to interpret what they read. They learn how to read but not how to learn while reading.

6. In mathematics, the results are, in general, poor and not uniform among countries. Students are not assimilating knowledge. Nor are they developing expected skills in mathematics. They do recognise symbols and structures on a basic level, but have difficulty solving both simple and complex math problems encountered in everyday life.

7. Achievement differences between schools are not explained by where a school is located or how it is funded; rather, differences between schools are related to teaching practices and to school management.

8. Most importantly, a favourable classroom learning environment, by itself, is more important for learning than the combined effect of all the other factors studied.

Although policies give high priority to equity, results are still modest. For example, although primary education increased in rural areas, only a smaller percentage of boys and girls reach the fifth grade. In general, girls do not suffer discrimination in terms of access to primary school. But such discrimination may exist in indigenous, rural, and marginal-urban contexts. Information about equity is scarce and not always reliable, so it is difficult to report confidently about education services for marginalised groups.

Financial investment in primary education has remained constant in most of Latin America, varying between one and four percent of gross domestic product. Although the decade saw a slight increase in public expenditure per student, this has not been significant. Lack of data on issues such as distribution of resources, relative weight of policy priorities, percentage of expenditures directed at marginalised groups, efficiency of spending, and private expenditure on education, inhibits strategic action. 
Teachers are key actors in improving the quality of education. They are the major source of instruction in most societies. In Latin America, except in rural areas, the supply of teachers, in absolute numbers, has been sufficient to meet demand. But approximately $20 \%$ of teachers do not meet the minimum qualifications set by their governments. There are great disparities between countries in their requirements for teacher certification. And although there are measures to promote better initial and in-service training, these have not yet produced significant changes in classroom practice.

\subsection{Literacy and education of young people and adults}

Within the region during the nineties, literacy training and education for young people and adults were not among policy priorities. This, together with the inefficiency of school systems, which in Latin America discard between 6 and 42 percent of students before they reach the fifth grade, caused increases in the total numbers of illiterates in some countries.

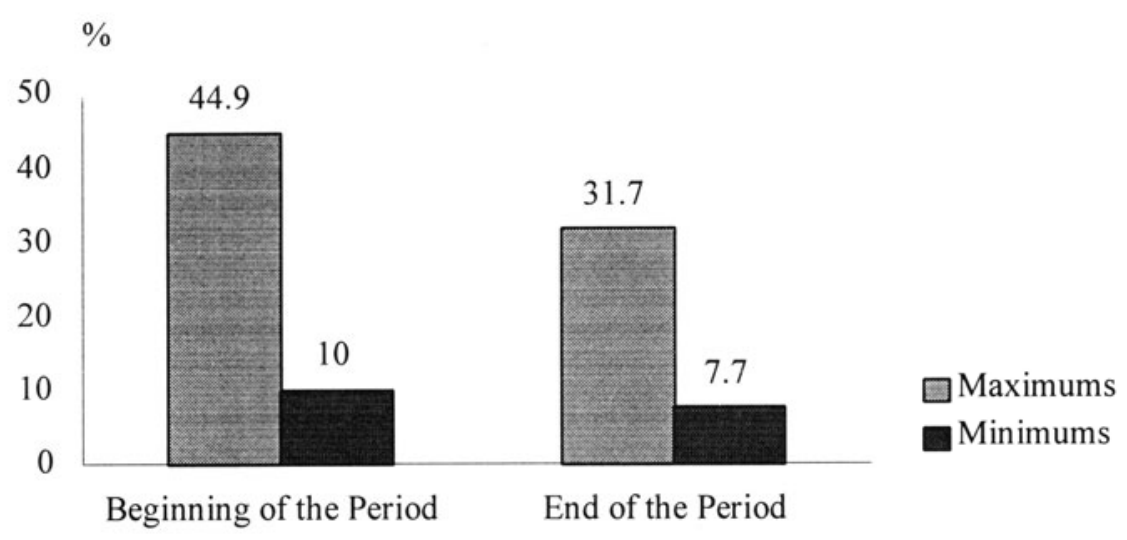

Figure 2. Adult literacy rate of the population aged 15 and older:

Ranges in Latin America

Illiteracy rates however fell in all countries, but without reaching the Jomtiem goal of reducing rates to half of the 1990 levels. Illiteracy is concentrated in the 24 years plus age group, in rural areas, low income zones of large cities, and among indigenous groups. Higher illiteracy in rural areas is due to delay in primary coverage reaching these areas and their poor 
performance in terms of retaining students in school until the fifth grade. There have been important changes in literacy training models.

Literacy training is now often combined with other education activities for young people and adults, such as job training; training increasingly occurs outside of the formal education sector. Also work preparation components have grown, in order to increase worker flexibility and mobility in a rapidly changing labour market. Literacy training programs have embraced multiple actors, from within and outside government.

In our continent, the majority of those attending adult programs are young people. There is a consensus about the priority areas for young people: a) preferential attention to post-primary education for those who live in poverty and have dropped out of primary programmes; b) the creation of programmes that stimulate active participation by young people and the full recognition of their responsibilities and rights; c) programmes that support and stimulate job training for young people living in poverty.

\subsection{Training in basic skills and education for a better life}

Schools in most countries now include learning components in human rights, values, ethics, concern for the environment, sexuality, and health. 'Education for life' themes occur across disciplines and as separate subjects. But with no assessment tools or systematic data, we do not know to what extent these subjects are addressed in schools; nor the impact that exposure to 'education for life' themes have on the daily life of students. Some countries make intense use of the media such as radio in the education of children and adults, particularly in rural and indigenous areas. The media is used for education in almost all the countries. The region does not have industries to develop and produce educational programmes for students, teachers, and the general public.

The use of computers and the Internet as teaching aids is only beginning in the region. Almost all countries have carried out projects to adopt these technologies in schools; some have set up national networks linking schools. A key question is how to utilise these new learning tools to encourage inclusion in education, and how to avoid hardware and software becoming factors resulting in greater inequality.

\subsection{Achievements, pending themes, and challenges}

Thus, among the major achievements in education during the nineties were:

- Universalisation of coverage of primary education

- Significant increases in coverage of early childhood education 
- A relative decrease in illiteracy

- A concern for quality

- A concern for equity

- The inclusion of education for life themes in both formal and nonformal, or alternative education programs

- Participation of multiple actors: NGO's, parents, social groups

- Education became a national priority.

The decade also left a number of themes pending:

- High rates of repetition and drop-out in primary school

- Scattered coverage for early childhood education, particularly for the 0 to 3 year age group

- Low priorities were placed on literacy training and the education of young people and adults

- Low student learning levels

- The persistence of social inequalities in the distribution, efficiency, and quality of education services

- Lack of communication and co-operation between different actors involved in the tasks of Education For All

- The need to strengthen governmental policy-making

- Small increases in investments in education.

So the major challenges faced by education in the future are:

- To transform education into a task for all through consensus- building, participation and co-ordination among actors

- To achieve greater participation from parents and communities

- To respond effectively to the multiple dimensions of education problems through policies that cut across all sectors of society

- To increase coverage of early education by promoting quality alternative programs

- To substantially improve primary school quality and to achieve effective learning of reading, writing, and math

- To substantially reduce rates of grade repetition and school drop-out

- To give greater priority to literacy training and to the education of young people and adults

- To improve opportunities for girls to learn math and science in the classroom

- To promote greater gender equity in rural areas and in indigenous communities

- To assess the impact of the teaching of education for life themes in both formal and non-formal programs 
- To encourage the use of the media and information technologies in order to promote equity

- To substantially increase public spending on early childhood education, primary education, literacy training, the education of young people and adults, education for life, and the use of the media and information technologies

- To increase the production, quality, and utilisation of data on education in order to improve decision-making at all levels of the system

- To increase education system efficiency and achieve greater transparency in the use of resources

- To substantially improve the initial training, work conditions, and social status of teachers.

\section{SECONDARY EDUCATION}

Secondary education was not included in the Education For All assessment. Nevertheless, the progress achieved in primary education during the nineties increased the demand for secondary education. The gross enrolment trends in secondary show a 10 percent growth between 1990 and 1997 , from 50.9 to $62.2 \%$. This increase represents both a quantitative advance, and also suggests access to secondary education by sectors that have hitherto been excluded through geographic, social, economic, and cultural factors.

Countries are implementing policies aimed at improving this secondary level. But it is the weakest link in the learning chain, with few clear definitions of its purposes, its structure, and functions, causing ambiguity and disfunctionality in approaches to secondary curricula. Traditionally, the secondary phase has been seen from two perspectives: either a scientific and humanistic bridge to higher education, or a specialised technical and vocational training leading to the labour market. This traditional view is lamentably out of date, exhibiting an unrealistic social perspective, disconnected from the concerns and needs of the population, society, and culture in which it is immersed. Traditional education based upon a juxtaposition of academic subjects, each one of them usually with a separate teacher, does not lend itself to a necessary unity and cohesion of approach. One damning criticism of secondary education is that it is divorced from the realities of everyday life, and that school knowledge is not transferable to day to day living. 


\section{THE FUTURE CONTEXT}

So what of the future, the context in which education will develop, the demands it will face, and the services needed to satisfy these demands and aid in constructing a more just society. This requires thought on future economic and social contexts for education.

\subsection{Sustainable development and the environment}

There is a consensus that projected world economic growth cannot be sustained unless we change current life-styles. What are the cultural obstacles to such a change - a change demanding new life styles, new beliefs, and new social relations. The idea of predictable market liberalisation ignores the fact that poorer nations need, besides a basic infrastructure, social investments in areas such as family planning, environmental protection, health care, and education - major public investments in social programmes.

During the last fifty years, the world's production of wealth has increased six-fold, never previously experienced. One cost has been pollution and environmental deterioration. The hope is that future, new, 'clean' technologies will aid heavy industries to develop non-polluting, earthfriendly processes; this requires educated and qualified people. Clearly, future generations must be able to live in a cleaner, healthier world, and the best way to protect the environment is through the development of technology and of education.

The last few decades have seen an ominous widening of the income gap in Latin America. A high proportion of children and young people remain outside of the school system through economic necessity. Malnourished millions live on the streets. Women, particularly rural women, have been doubly hit by the increase in poverty. Often it is difficult for women to attend class because either as children as adults, they are heads of households. Currently, women head $20 \%$ of households of Latin American families. So, one challenge for the future is to reverse this trend toward evergreater poverty and assure that the education systems themselves do not reproduce social inequalities.

\subsection{Knowledge and information}

The production and accumulation of knowledge are the driving force for development. Currently, the production of scientific and technological knowledge in the region is precarious. It is necessary to come up to speed internationally to be part of the technological revolution and to survive in an 
increasingly competitive world. Training must be intensified in scientific and technological research, so people can face the new challenges of the global economy.

Information technology will profoundly transform the way that people organise their lives, interact with others, and participate in all areas of social life. We should be aware, however, of the social impact of these new information technologies - the effect they will have on work, education, culture, health, business, and public services.

\subsection{Demographic aspects}

The population growth rate has decreased in wealthy countries, and has remained high in poor countries. The fertility rate is inversely related to the literacy rate of adult women; consequently, the population of developed countries is ageing, while the demographic structure in developing countries is younger.

Nevertheless, in Latin America, population growth projection curves show an important downward trend. From the $16 \%$ growth figure for the years 1995 to 2000 , they should drop to $10.6 \%$ between 2015 and 2020 . The proportion of the population below 16 years is estimated to fall from $31.6 \%$ in the year 2000 to $24.9 \%$ in the year $2020{ }^{1}$ So the increase in demand for education will grow for young adults, and relatively diminish for the 5 to 14 year group. For OECD countries (Education at a Glance. OECD Indicators, 1998), in 1996 the percentage of the population between 35 and 44 years with studies after secondary school was $65 \%$ for men and $60 \%$ for women. In Latin America and the Caribbean, these percentages are 26\% and 33\%. Enormous efforts will be required, for our region to at least equal the situation of the developed countries in 1996.

Education impacts on population growth rates. For each additional year of education that a girl receives, the infant mortality rate drops and the birth rate falls. Access to more and better education also raises education levels of parents leading to decreasing dropout rates and raising achievement levels of their children.

\section{EDUCATION SERVICES: DEMAND AND SUPPLY}

What about the future demand for education and the response from education systems?

' Boletin Demográfico Nro. 64, CELADE - CEPAL, julio 1999. 


\subsection{Future demand for education}

Among the demands placed upon education, we should note those directed at: a) assuring human development and improving the quality of life, preservation of the environment, overcoming poverty, and achieving education that excludes no one; b) contributing to regional integration and to strengthening citizenship skills; c) strengthening the development of science and technology; and d) improving working conditions.

\section{a. Human Development and the Quality of Life}

Education is the key for the development of individuals as well as the development of society. At the World Education Conference in Jomtien in 1990 it was declared:

Each person, children, young people, and adults, should be able to have access to education options in order to satisfy his or her basic learning needs. These needs include essential learning tools (such as reading, writing, oral expression, arithmetic, and problem-solving), as well as basic learning content itself (theoretical and practical knowledge, values, and attitudes) necessary to permit human beings to survive, to fully develop their abilities, to live and work with dignity, to fully participate in development, to improve the quality of their lives, to make basic decisions, and to continue learning.

This recognises that:

The satisfaction of these needs confers on people the possibility and, at the same time, the responsibility, of respecting and enriching their cultural, linguistic, and common spiritual heritage, of promoting the education of all, of defending the cause of social justice, of protecting the environment, and of being tolerant of social, political, and religions systems that are different from their own, respecting humanistic values and commonly accepted human rights, as well as working for international peace and solidarity in an increasingly interdependent world.

The Delors Report (UNESCO 1996) established four pillars as the foundation for tomorrow's learner - learn to know, to do, to live together, and to be.

In learning to know, people require:

1. The ability to concentrate, to use memory and thought as the basis for learning;

2. The ability to seek out and analyse available information; 
3. The ability to take active control of their own education, to adapt to the environment and to existing possibilities;

4. The understanding that learning is not a linear process nor a single event, but rather a wide process that moves forward by means of a great variety of experiences outside of the classroom.

In learning to do, people require:

1. To recognise that learning is a practical process which is not solely based on abstraction and theoretical discussion;

2. To go back and forth between school-based learning and every-day experience in order to integrate knowledge an action;

3. Aptitudes and abilities to act based more on general competence than on specific task-related skills;

4. Scientific and technical reasoning skills due to the importance that this kind of knowledge has for human development.

In learning to live together, people require:

1. The ability to participate in democratic processes within a spirit of building peace;

2. An open and accepting attitude toward peoples and cultures;

3. The ability to learn anywhere and to recognise that the community is responsible for the education of its members;

In learning to be, people require:

1. Self-responsibility and participation in the common goals of the community;

2. Integrated knowledge of the potentialities of human beings, including an aesthetic sense, an appreciation for sport and for culture;

3. An understanding that having is not the same as being;

4. Education that contributes to their full spiritual, physical, and ethical, development.

An important trait for young people is the ability to adopt a pro-active, autonomous and self-confident attitude toward life. Quality life-long education for all should encourage creativity, flexibility to adapt to change, the development of intelligence, the ability of self-initiative, sociability, solidarity, self-esteem, self-confidence, and ethical integrity.

The greatest challenge faced by education in Latin America is to effectively contribute to overcoming poverty and social inequalities. Most poor children still receive poor quality education that does not enable them to break out of the vicious circle of poverty. An accepted meaning of equality of educational opportunities is for all to be able to enrol in an education system. But who enters, into what kinds of establishments, and with what kind of 'cultural capital'? For education to become an effective tool in the struggle against poverty and inequality, we must differentiate the 
financing so the State can provide compensatory resources for those children entering with less 'cultural capital'.

\section{b. Regional Integration and Globalisation}

Globalisation has made us aware of the need for Latin American integration as a means to strengthen cultural identity. Cultural trends in the past were distinguished by lack of recognition, or even disdain between neighbours; as if one built cultural identity by affirming one's own traditions and rejecting those of others. This kind of thinking must change. People must learn to recognise and value differences as positive factors in the construction of a durable regional cultural identity.

This has direct implications for the school curriculum, such as the obligation to teach foreign languages, a history that emphasises common projects and achievements more than wars and divisions, a history that takes a positive, rather than a negative view of neighbouring countries. More effort is needed to certify study, from primary to university, taken in other countries to facilitate our social, economic, and cultural integration.

Education is being called upon to play a key role because it is uniquely able to encourage the positive aspects of globalisation and reduce possible negative ones.

\section{c. Generation and Incorporation of Knowledge and Technologies}

The production and utilisation of knowledge are increasingly important so that countries may achieve long-range, sustainable economic growth. Education must be both efficient and responsible in training citizens able to produce new knowledge and use it creatively. In the future, such a focus has the advantage of remaining up to date as it constantly seeks to narrow the gap between education systems and the future requirements of societies.

Everyone should have access to and use technology. Without this, we will increase the distance between more and less developed countries. Train for its use and development, incorporating it into daily life is a task for education. Developing countries have invested little in preparing scientists. This should create a concern to extend science education to all, to increase the training of scientists, and to demystify the daily use of technology.

The link between scientific and technological development and education has been absent, in most cases, in the definition of education policies. Improving training in science, particularly on the secondary school level, requires more and better-trained teachers. Countries that do not develop integrated policies of scientific and technological development with education components are taking a short-range view. But in an integrated 
policy, a high priority should be given to those aimed at financing national investment in science and technology. To do so we must be highly creative and original, as well as being aware of financing models successfully used by developed countries.

The relationship between competition and education has never been closer. We must make great efforts to diminish the gap between developed countries and us. It is not only the case of the need to produce and make use of knowledge. We must ensure that knowledge and technologies are widely disseminated and used by all of the population.

\section{d. The World of Work}

It is predicted that in the coming years the labour conditions of the population will change. People who remain in the same job will change the way they work. The informal sector of the economy will continue to grow, and with it the vicious cycle of unstable occupations, low productivity, low incomes, and the impossibility of absorbing advanced technology.

Education, therefore, must look into the future and visualise a labour situation both different and more vulnerable that the present one. The ability to work in small groups; to use of communication technologies; to be a 'selfstarter' and to develop and adapt to the informal market; to make more and better use of free time (shorter working days), should all be the objectives of training in both the formal and non-formal education sectors.

Most of these changes will have profound impacts on education. Among areas that require attention is higher education, which is not yet fully sensitive to the demands of the market. Adult education and informal, leisure learning will be affected as well. We do not need to know precisely for which kind of occupation we should educate our young people, or re-train adults. Education must be more open in order to train individuals who are creative, able to solve problems, and who can accept change. Since technological innovations create new occupations or eliminate others, countries that are not prepared to train or re-train their labour force will be at a serious disadvantage.

\subsection{The supply of education services}

Education systems must respond to demands for the need for a new kind of school, a new kind of curriculum, a new kind of teacher, and new actors.

\section{a. New Schools that are Open and Autonomous}


If we want education to change, we have to change school. Schools are among the institutions most alienated from our societies. Generally, most of the important decisions are taken outside of the school itself. Decisions such as the nomination of its teachers and directors; regarding curriculum, tests, and assessment; about the training of its teachers, have been based more on central plans than of considerations of teachers' real needs. Decisions on resources and how they are used come from a central administration.

The new school must be based on administrative, financial, and pedagogical autonomy. Each school should manage its own personnel, make decisions regarding the school calendar and strategies to track and assess learning achievement. It should be able to include in the curriculum subjects that are of interest to the community of which it is a part. School management should be a joint responsibility between teachers, parents, and local authorities. In order for this autonomy to function well, all actors should be prepared and trained to work together. Inputs and processes should be subordinated to student learning. An efficient school should establish a longer, more assiduous, more intense school day. Current education reforms have witnessed some interesting experiences aimed at providing incentives for autonomy and creativity in schools. These positive trends should be strengthened until schools are transformed so that, besides carrying out their fundamental missions, they become true socialising agents and community centres.

\section{b. A New Curriculum and Education Resources}

School curricula should be profoundly transformed in order to change the current compartmentalised, subject design. Crosscutting themes should be incorporated which contribute to the integral training of students, and which respect multiple intelligences. It could be a curriculum more centred on facilitating learning to know, to do, to live together, and, especially, to be. This kind of knowledge would thus help to counter one of the most worrisome fears of our times: the fear of not finding a meaning to life.

Education systems should consider new styles of learning marked by greater autonomy of the learner and the utilisation of new technologies. The communication media and information technologies within the school system can make education available to more people - even the most distant. A more flexible system is needed that makes learning opportunities available to people throughout their lives. The new curriculum must take into account the multiple possibilities of learning that occur outside of the classroom. By doing so, the school can both develop and strengthen in people critical thinking in regard to the media. Course content in the curriculum cannot be an end in itself. It make no sense to study language if the purpose is not to 
communicate more effectively orally and in writing. Nor does it make sense to study history if this does not serve to develop a critical and constructive attitude vis-à-vis society. Memorising is not learning; learning must be used to progress in the world, more autonomously and more creatively.

\section{c. The New Teacher}

A pending task is the training of a group of professionals able to introduce and carry out these profound changes that the education system needs. To educate in new skills for a more developed society demands teachers with different characteristics, teachers who are innovative and have self-initiative. To prepare such teachers, we must support initial and inservice training. This requires: a) the creation of in-school meeting places where teachers can reflect, exchange experiences, provide mutual support, and create teaching materials; b) national and international policies for exchange of teachers and innovative experiences; c) resources for research and creative thinking; d) reform of teacher training courses. Special attention should be given to experiments with teaching programmes based on the use of new information and communication technologies.

Schools will not change without first changing the teachers. We need less bureaucratic teachers, teachers willing and able to take the initiative and who can use their professional knowledge to help solve the learning challenges of their students. A teacher with initiative does not need to directed from someone outside the classroom. Assessments of the learning achievements of the students of such a teacher do not have to come from outside. He or she does not have to be told that such and such a content must be given in such and such a time. So the education system must remove bureaucratic barriers, and create necessary conditions for freeing the self-initiative and creativity of teachers. A teacher with self-initiative knows how to diagnose the learning problems of each student, propose adequate measures, and track the situation until the problem is solved. This is to say that, as a professional, the teacher should assume responsibility for student learning. But such a teacher deserves and requires a better salary and better working conditions than are the norms in our region. We should think about systems with flexible, competitive salaries which reward good teachers, salaries with fixed and variable components, with criteria that reward merit, with control systems that are close to the municipality and to the school. All of this means that much effort must be given to the selection and training of teachers who have a new mentality. We must create new stimuli such as premiums, scholarships, training courses, and salary incentives for those who work under difficult conditions in rural or distant areas. A teacher with self- 
initiative is the single most effective tool in the school, such a teacher both teaches and learns at the same time.

Education systems should concern themselves with themes of universitybased initial and in-service training of science teachers, particularly for the secondary level. Reinforcing national capacity for the development of education material in science is fundamental if we wish knowledge of science and technology to be presented appropriately to students.

A new school requires a new school director. Besides the technical competence required for the position, besides pedagogical and administrative skills, the school director must have leadership skills as well. This is important not only in order to create a team spirit in the school among teachers and students. It is vital in order to involve the community in the life of the school and the school in the life of the community. The success of a school is in large measure dependent upon the dynamism and competence of its director.

\section{d. New Actors}

If we wish the whole society to be educated, we need new actors who participate in the tasks of education. A policy of inclusion requires a change of responsibility in school management. This raises a number of questions about the roles of the State, the private sector, and society in educational change. Besides a more marked and more dynamic participation of teachers and of parents in the process, education should be a responsibility shared by all: journalists, business people, churches, legislators, and other governmental authorities not connected to education. Quality education for all, throughout life, demands from everyone a new viewpoint. Each sector of society should reflect on its role and do all it can in the creation of a more human and more just society, with citizens who are better educated and more able to live in an ever more complex world.

\section{CONCLUSIONS}

These reflections allow us to identify a set of requirements for consideration when thinking about education systems in the future. All of them apply to the world as a whole, but they have special relevance in Latin America.

- Because of the complex demands placed upon them in terms of human development, quality of life, integration, globalisation, the challenges of the knowledge and use of technology and it effects on work, the education system is of the utmost importance. 
- We need to imagine the building of an education system that is flexible, open to all, independent of age or life conditions; a system that guarantees that education as a right throughout life. We need to imagine a system that is open to those who have already been to school, allowing them to return. We need to think of an open system that incorporates all educational resources in the society, including the media and new communication technologies.

- We need to achieve an educating society, involved and aware that responsibility is shared, and that education is everyone's task, not only that of those traditionally involved in the sector.

- The development of science and technology must be undertaken with responsibility not increase the gap between rich and poor countries. We need more scientists; we need to increase the use of technology, particularly for the improvement of learning.

- We should move towards education that considers both the transmission of knowledge and the development of all of person's potential. The strengthening of democracy, the maintenance of peace, the fostering of development all demand education with a profound ethical meaning; an ethics of solidarity which is manifested in daily life, in politics, in business, and in interpersonal relations.

- It is evident that people must be trained to adapt themselves to changing situations, to possess cultural fluency with respect for other cultures, to be able to prevent and to solve problems, and to be self-motivating, able to become permanent learners.

- Regional integration, globalisation, and respect for one's identity demand an education that respects diversity, that allow us to successfully face the tensions between the world and the community, between tradition and modernity, between what is global and what is personal.

- Improving the professional and social status of teachers is crucial for a new kind of education appropriate for the new millennium. Initial and in-service teacher training must convince teachers that they are not only teachers, but learners as well.

- As in any other system, the education system needs to be managed with competence and accountability. Until recently, the use of management tools in education was unheard of; today it is clear without such techniques, it will be more difficult to obtain the financial, material, and human resources required for transformation.

What happens in the coming years will have a decisive impact on the future well being of our planet and all of us who inhabit it. Much will depend on the kind of education that we offer our citizens. Schools, as they have always been, are our last and best hope. 


\section{BIOGRAPHY}

Ana Luiza Machado has been Director of UNESCO's Regional Office for Education in Latin America and the Caribbean since 1997. She holds a degree in Social Sciences from the Federal University of Minas Gerais (Brazil) and completed post-graduate courses in Business Administration offered by Columbia University (NY) in collaboration with the João Pinheiro Foundation and FUMEC (Brazil). In addition, she is certified in Organizational Consulting by the Business Administration Council of the National Business Studies Service (SENAC, Brazil). She worked as a planning and research specialist at the João Pinheiro Foundation (Brazil) from 1971-1988, and as a consultant in business organization for the private and public sectors, principally in the area of education. She was Deputy Secretary of Education of the State of Minas Gerais from 1991-93. From 1993-1996 she was that State's Secretary of Education. Under her leadership, the state successfully carried out major reforms in education. In January, 1995 she was elected President of the National Council of State Secretaries of Education (CONSED), serving in that post until December, 1996. She was a member of Brazil's National Education Council from 1996-97. 